\title{
PI3K-Akt-Wnt Pathway Is Implicated in Exercise-Induced Improvement of Short-term Memory in Cerebral Palsy Rats
}

\author{
Jung-Wan Cho ${ }^{1}$, Sun-Young Jung ${ }^{2}$, Dae-Young Kim³ ${ }^{3}$, Yong-Rak Chung ${ }^{4}$, Hyun-Hee Choi ${ }^{5}$, Jung-Won Jeon ${ }^{6}$, Jin-Hee Han ${ }^{7}$ \\ ${ }^{1}$ Department of Physical Therapy, Kyung Hee University Medical Center, College of Medicine, Kyung Hee University, Seoul, Korea \\ ${ }^{2}$ Department of Physical Therapy, Hosan University, Gyeongsan, Korea \\ ${ }^{3}$ Department of Sports Healthcare, College of Humanities \& Social Sciences, Inje University, Gimhae, Korea \\ ${ }^{4}$ Department of Golf Mapping, College of Arts Physical Education, Joongbu University, Geumsan, Korea \\ ${ }^{5}$ Division of Leisure \& Sports Science, Department of Exercise Prescription, Dongseo University, Busan, Korea \\ ${ }^{6}$ Department of Internal Medicine, Kyung Hee University Hospital at Gandong, College of Medicine, Kyung Hee University, Seoul, Korea \\ ${ }^{7}$ Department of Anesthesiology and Pain Medicine, Kyung Hee Medical Center, College of Medicine, Kyung Hee University, Seoul, Korea
}

Purpose: Maternal lipopolysaccharide (LPS) injection induces neurodevelopmental disorders, such as cerebral palsy. Exercise activates phosphatidylinositol 3-kinase (PI3K)-protein kinase B (Akt) signaling pathway that enhances neurogenesis. Wnt ligands are also implicated in the hippocampal neurogenesis and synaptic plasticity. Glycogen synthase kinase-3 $\beta$ (GSK-3 $\beta$ ) is a downstream molecule of Akt, and GSK-3 $\beta$ is known to modulate hippocampal neurogenesis negatively.

Methods: Cerebral palsy was made by maternal LPS-injection. On the 5 weeks after birth, treadmill running was applied to the rat pups of the exercise groups, for 30 minutes, 5 times a week during 6 weeks.

Results: Treadmill running alleviated short-term memory impairments of the cerebral palsy rat pups. Hippocampal cell proliferation was increased and hippocampal apoptosis was suppressed by treadmill running in the cerebral palsy rat pups. Hippocampal phosphorylated-PI3K/PI3K ratio, phosphorylated-Akt/Akt ratio, and Wnt expression were enhanced by treadmill

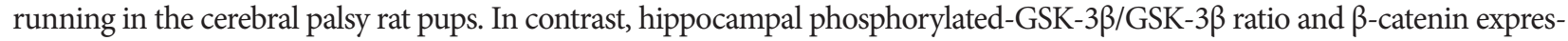
sion were suppressed by treadmill running in the cerebral palsy rat pups.

Conclusions: The results of this study showed that short-term memory improvement due to treadmill running in cerebral palsy occurs via activation of the PI3K-Akt-Wnt pathway.

Keywords: Cerebral palsy; Short-term memory; Phosphatidylinositol 3-kinase; Protein kinase B; Glycogen synthase kinase-3 $\beta$

- Research Ethics: All animal experimental procedures were approved by the Institutional Animal Care and Use Committee of Kyung Hee University (KHUASP[SE]-16-108), and performed in accordance with the National Institute of Health Council for the management and use of laboratory animals.

- Conflict of Interest: No potential conflict of interest relevant to this article was reported.

\section{- HIGHLIGHTS}

- Treadmill running alleviated short-term memory impairments in the cerebral palsy rat pups.

- Treadmill running facilitated hippocampal cell proliferation and reduced hippocampal apoptosis of cerebral palsy rat pups.

- Exercise-induced improvement of short-term memory in cerebral palsy occurs through PI3K-Akt-Wnt pathway.

Corresponding author: Jin-Hee Han (iD http://orcid.org/0000-0003-0399-1148 Department of Anesthesiology and Pain Medicine, Kyung Hee Medical Center, College of Medicine, Kyung Hee University, 23 Kyungheedae-ro, Dongdaemungu, Seoul 02447, Korea

E-mail: esthesi@khu.ac.kr / Tel: +82-2-958-8589 / Fax: +82-2-958-8580

Submitted: September 1, 2018 / Accepted after revision: October 7, 2018
This is an Open Access article distributed under the terms of the Creative Commons Attribution Non-Commercial License (http://creativecommons.org/licenses/by-nc/4.0/) which permits unrestricted non-commercial use, distribution, and reproduction in any medium, provided the original work is properly cited. 


\section{INTRODUCTION}

Lipopolysaccharide (LPS) is one of the important structural elements found in the gram-negative bacteria, and LPS has been used to make an inflammatory animal model. Maternal LPS injection induces neurodevelopmental disorders, such as cerebral palsy [1,2]. Cerebral palsy is a static neurological condition and characterized by motor deficits and cognitive impairments [3].

Apoptosis recognized as an essential step in the nerve development and naturally occurring nerve cell death, however, excessive apoptosis causes diverse neuropsychiatric disorders [47]. Terminal deoxynucleotidyl transferase-mediated dUTP nick end labeling (TUNEL) staining has been used as a tool for the detection of DNA fragmentation, and then TINEL-positive cells represent apoptotic cell death $[4,6]$. Physical exercise increases neurotrophic factors, facilitates neurogenesis, decreases apoptosis, and then improves cognitive function $[4,5,7]$. Treadmill running for 12 weeks increased cerebral blood flow, which resulted in enhancing hippocampal neurogenesis [8].

Exercise is known to promote the production of neurons by activating the signaling pathway of phosphatidylinositol 3-kinase (PI3K)-protein kinase B (Akt) [2,9]. Akt is a downstream molecule of PI3K, which regulates cell proliferation, cell surviv$\mathrm{al}$, and metabolism [10]. Wnt-3 is a proto-oncogene protein in humans, and Wnt- 3 is encoded by the WNT3 gene. Wnt signaling modulates diverse biological pathway and has relation with many developmental diseases $[11,12]$. Wnt ligands are also implicated in the hippocampal neurogenesis and synaptic plasticity [13], and this pathway is activated by physical exercise [12,14]. Stranahan et al. [15] showed that enhanced Wnt expression in the hippocampus after voluntary exercise improved hippocampal plasticity and cognitive function. Overexpression of hippocampal Wnt increased neurogenesis, meanwhile, inhibition of Wnt pathway suppressed neurogenesis [16]. Tiwari et al. [17] suggested that control of hippocampal neurogenesis is closely related with the activity of PI3K-Akt-Wnt signaling pathway.

Hippocampal neurogenesis is negatively affected by glycogen synthase kinase-3 $\beta$ (GSK-3 $\beta$ ) [18]. GSK-3 $\beta$ is a downstream molecule of Akt-mediated signal transduction, and activation of Akt signaling suppresses phosphorylation of GSK-3 $\beta$. [10]. Physical exercise facilitates Akt activity and decreases GSK-3 $\beta$ expression [19]. $\beta$-Catenin is a primary molecule of Wnt signaling pathway, and GSK- $3 \beta$ is critically implicated in the Wnt pathway [20]. Destruction cycle of neural cells is initiated by phosphorylation of $\beta$-catenin through GSK-3 $\beta$ [21]. When Wnt pathway acts on neural cells, Wnt inhibits GSK-3 $\beta$, thereby stabilizes and decreases expression of $\beta$-catenin [18].

Using the rat pups, we investigated the effect of treadmill running on cerebral palsy-induced short-term memory impairments. We also evaluated whether PI3K-Akt-Wnt pathway is associated with the exercise-induced improvement of shortterm memory of the cerebral palsy.

\section{MATERIALS AND METHODS}

\section{Treatments of Animals}

All animal experimental procedures were approved by the Institutional Animal Care and Use Committee of Kyung Hee University (KHUASP[SE]-16-108), and performed in accordance with the National Institute of Health Council for the management and use of laboratory animals. Sprague-Dawley female rats ( $190 \pm 5 \mathrm{~g}$, 9 weeks in age, $\mathrm{n}=12)$ were mated with male rats ( $190 \pm 5 \mathrm{~g}$, 9 weeks in age, $\mathrm{n}=12)$ during one day. And then, the female rats were housed at home cages individually under the controlled conditions (temperature: $20^{\circ} \mathrm{C} \pm 2^{\circ} \mathrm{C}$, lights on from 7:00 AM to 7:00 PM).

As the previously described method [2], offspring with cerebral palsy were made. The pregnant rats were classified as control and LPS-injection group ( $\mathrm{n}=6$ for each group). One $\mathrm{mL}$ of $0.15 \mathrm{mg} / \mathrm{kg}$ LPS (Sigma Chemical Co., St. Louis, MO, USA) diluted in pyrogen-free saline (PFS) was intracervical injected to the pregnant rats in the maternal LPS-injection group, during the 15th, 17th, and 20th day of pregnancy. For the pregnant rats of the control group, PFS was injected. After delivery, the rat pups were re-grouped as control, exercise, cerebral palsy, and cerebral palsy and exercise group $(\mathrm{n}=8)$.

\section{Treadmill Running Protocol}

On the 5 weeks after delivery, treadmill running for 30 minutes per a day, 5 times per a week, for 6 weeks was conducted in the rat pups of the exercise groups. The load speed was running at $2 \mathrm{~m} /$ min during 5 minutes, at $5 \mathrm{~m} / \mathrm{min}$ speed during 5 minutes, and at $8 \mathrm{~m} / \mathrm{min}$ during 20 minutes with no inclination.

\section{Step-Down Avoidance Task}

By the previously performed method [7,22], short-term memory was determined by step-down avoidance task. The rat pups positioned and took rest on the platform $(7 \mathrm{~cm} \times 25 \mathrm{~cm}$ with a height of $2.5 \mathrm{~cm}$ ) during 1 minute. The platform consists of a 42 $\mathrm{cm} \times 25 \mathrm{~cm}$ grid of $0.1-\mathrm{cm}$ diameter stainless steel bars parallel 
to each other at $1-\mathrm{cm}$ intervals. For the training of the rat pups, scramble foot shock at $0.5 \mathrm{~mA}$ for 2 seconds was applied to the rat pups when immediately coming down from the platform. At 48 hours after training session, retention time was determined. The latency was calculated as the time from when the rats descended from the platform and all 4 feet reached the grid. Latency greater than 300 seconds was calculated as 300 seconds.

\section{Tissue Preparation}

Zoletil 50 (10 mg/kg intraperitoneally; Vibac Laboratories, Carros, France) was used to anesthetized the rat pups. After that, $50 \mathrm{mM}$ phosphate-buffered saline (PBS) was transcardially perfused, and then the rat pups were subsequently fixed by $500 \mathrm{mM}$ phosphate buffer $(\mathrm{pH}, 7.4)$ containing $4 \%$ paraformaldehyde. After the brains were removed, the brains were fixed using the same fixation solution during overnight. And then, the brains were treated with a $30 \%$ sucrose solution for cryoprotection. By a freezing microtome (Leica, Nussloch, Germany), coronal sections of $40 \mu \mathrm{m}$ were made.

\section{TUNEL Staining}

As the previously described method [6,22], TUNEL staining was conducted by an In Situ Cell Death Detection Kit (Roche, Mannheim, Germany). The brain sections were treated with $10 \mathrm{mM}$ Tris- $\mathrm{HCl}$ buffer $(\mathrm{pH}, 8.0)$ at $55^{\circ} \mathrm{C}$ for 30 minutes, treated with proteinase $\mathrm{K}(100 \mu \mathrm{g} / \mathrm{mL})$, treated with $3 \% \mathrm{H}_{2} \mathrm{O}_{2}$, permeabilized with $0.5 \%$ Triton X-100, and then treated with a TUNEL reaction mixture. By the Converter-POD with 0.03\% 3,3'-diaminobenzidine (DAB), the sections were visualized. After the slides were dried under the room conditions, Permount (Fisher Scientific, Fair Lawn, NJ, USA) was used for the coverslips mounting.

\section{Immunohistochemistry for 5-Bromo-2'-Deoxyuridine}

As the previously described method [4,22], 5-bromo-2'-deoxyuridine (BrdU) immunohistochemistry was performed. The brain sections were treated with $0.5 \%$ Trioton X-100 in PBS for 20 minutes, treated with $50 \%$ formamide- $2 \mathrm{x}$ standard saline citrate at $65^{\circ} \mathrm{C}$ for 2 hours, treated with $2 \mathrm{~N} \mathrm{HCl}$ at $37^{\circ} \mathrm{C}$ for 30 minutes, and then treated with $100 \mathrm{mM}$ sodium borate $(\mathrm{pH}, 8.5)$. The sections were treated with mouse monoclonal anti-BrdU antibody (1:600; Roche) during overnight at $4^{\circ} \mathrm{C}$, treated with biotionylated mouse secondary antibody (1:200; Vector Laboratories, Burlingame, CA, USA) for 90 minutes, and treated with avidin-peroxidase complex (1:100; Vector Laboratories). To visualize, the section was treated with $50 \mathrm{mM}$ Tris- $\mathrm{HCl}(\mathrm{pH}, 7.6)$ in $0.02 \% \mathrm{DAB}, 40-\mathrm{mg} / \mathrm{mL}$ nickel chloride, and $0.03 \% \mathrm{H}_{2} \mathrm{O}_{2}$ during 5 minutes. With a mouse monoclonal anti-neuronal nucleic antibody (1:300; Chemicon International, Temecula, CA, USA), counter-staining was conducted upon the same sections. After the slides were dried under the room conditions, Permount (Fisher Scientific) was used for the coverslips mounting.

Under the light microscope (Olympus, Tokyo, Japan), BrdUpositive cell number in the hippocampal dentate gyrus was hemilaterally detected. After measuring the dentate gyrus area by the Image-Pro Plus image analysis system (Media Cybernetics Inc., Silver Sprng, MD, USA), BrdU-positive cell number was presented as the number of cells per $\mathrm{mm}^{2}$ of the dentate gyrus.

\section{Western Blot Analysis}

As the previously described method [2,6], Western blotting was performed. After transferring proteins onto nitrocellulose, the blots were probed. As the primary antibodies, mouse monoclonal anti-Wnt-3 antibody (1:1,000, Santa Cruz Biotechnology, Inc., Santa Cruz, CA, USA), mouse monoclonal anti-PI3K antibody (1:1,000, Santa Cruz Biotechnology), rabbit polyclonal anti-p-PI3K antibody (1:1,000, Santa Cruz Biotechnology), rabbit polyclonal anti-Akt antibody (1:1,000, Cell Signaling Technology Inc., Beverly, Massachusetts, USA), rabbit polyclonal anti-p-Akt antibody (1:1,000, Cell Signaling Technology), rabbit polyclonal anti-GSK-3 $\beta$ antibody (1:1,000, Santa Cruz Biotechnology), rabbit polyclonal anti-p-GSK-3 $\beta$ antibody (1:1,000, Santa Cruz Biotechnology), and mouse monoclonal anti- $\beta$-catenin antibody (1:1000, Santa Cruz Biotechnology) were used. For the secondary antibodies, peroxidase anti-rabbit IgG antibody (1:5,000, Vector Laboratories) and peroxidase anti-mouse IgG antibody (1:10,000, Vector Laboratories) were used. For the detection of immunoreactivity, we used enhanced chemiluminescence detection kit (Santa Cruz Biotechnology).

\section{Results Analysis}

For the statistical analysis, 1-way analysis of variance with the Duncan post hoc test was performed. Mean \pm standard error of the mean was presented for the expression of results, and $\mathrm{P}<0.05$ was determined as a statistical significance.

\section{RESULTS}

\section{Short-term Memory}

Fig. 1 is data of the short-term memory determined by stepdown avoidance task. The latency of the cerebral palsy rat pups 
was less than the normal rat pups $(\mathrm{P}<0.05)$, meanwhile, treadmill running lengthen this latency of the cerebral palsy rat pups $(\mathrm{P}<0.05)$.

\section{Hippocampal Cell Proliferation}

Fig. 2 is photomicrographs showing hippocampal BrdU-positive cells. BrdU-positive cell number in the cerebral palsy rat pups was less than the normal rat pups $(\mathrm{P}<0.05)$, meanwhile, treadmill running enlarged this number of the cerebral palsy rat pups $(\mathrm{P}<0.05)$.

\section{Hippocampal DNA Fragmentation}

Fig. 3 is photomicrographs showing hippocampal TUNELpositive cells. TUNEL-positive cell number in the cerebral palsy rat pup was higher than the normal rat pups $(\mathrm{P}<0.05)$, meanwhile, treadmill running lessened this number of the cerebral palsy rat pups $(\mathrm{P}<0.05)$.

\section{Hippocampal PI3K and p-PI3K Expression}

Fig. 4 is Western blot analysis showing hippocampal PI3K and $\mathrm{p}$-PI3K expression. The $\mathrm{p}-\mathrm{PI} 3 \mathrm{~K} / \mathrm{PI} 3 \mathrm{~K}$ ratio was less in the cerebral palsy rat pups $(\mathrm{P}<0.05)$, meanwhile, treadmill running enlarged $\mathrm{p}-\mathrm{PI} 3 \mathrm{~K} / \mathrm{PI} 3 \mathrm{~K}$ ratio by facilitating $\mathrm{p}$-PI3K expression of the cerebral palsy rat pups $(\mathrm{P}<0.05)$.

\section{Hippocampal Akt and p-Akt Expression}

Fig. 5 is Western blot analysis showing hippocampal Akt and pAkt expression. The p-Akt/Akt ratio was less in the cerebral palsy rat pups $(\mathrm{P}<0.05)$, meanwhile, treadmill running enlarged $\mathrm{p}$ -

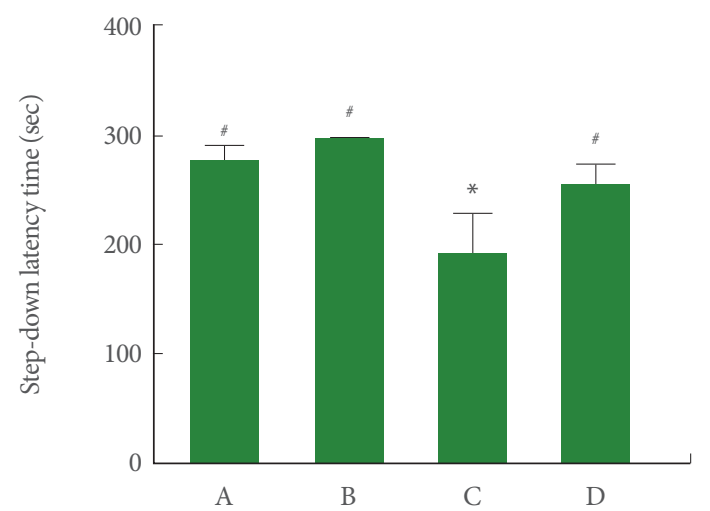

Fig. 1. Effect of treadmill exercise on the short-term memory. A, control group; B, exercise group; C, cerebral palsy group; D, cerebral palsy and exercise group. ${ }^{*} \mathrm{P}<0.05$ compared to the control group. ${ }^{*} \mathrm{P}<0.05$ compared to the cerebral palsy group.
Akt/Akt ratio by increasing p-PI3K expression of the cerebral palsy rat pups $(\mathrm{P}<0.05)$.

\section{Hippocampal Wnt-3 Expression}

Fig. 6 is Western blot analysis showing hippocampal Wnt-3 expression. The Wnt-3 expression was less in the cerebral palsy rat pups $(\mathrm{P}<0.05)$, meanwhile, treadmill running enlarged Wnt-3 expression of the cerebral palsy rat pups $(\mathrm{P}<0.05)$.

\section{Hippocampal GSK-3 $\beta$ and p-GSK-3 $\beta$ Expression}

Fig. 7 is Western blot analysis showing hippocampal GSK-3 $\beta$ and $p$-GSK- $3 \beta$ expression. The $p-G S K-3 \beta / G S K-3 \beta$ ratio was
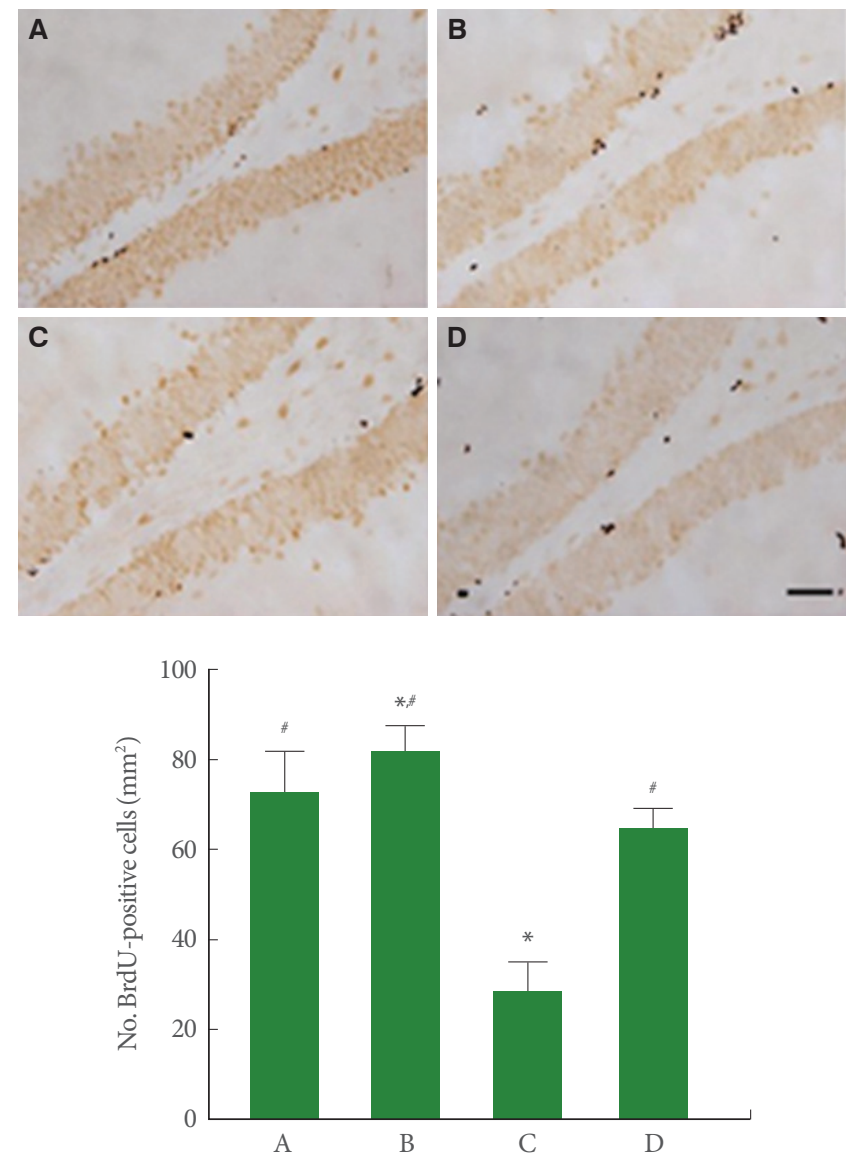

Fig. 2. Effect of treadmill exercise on cell proliferation in the hippocampal dentate gyrus. Upper panel: Photomicrographs of 5-bromo-2'-deoxyuridine (BrdU)-positive cells in the hippocampal dentate gyrus. The scale bar represents $200 \mu \mathrm{m}$. Lower panel: Number of BrdU-positive cells in each group. A, control group; $\mathrm{B}$, exercise group; $\mathrm{C}$, cerebral palsy group; $\mathrm{D}$, cerebral palsy and exercise group. ${ }^{*} \mathrm{P}<0.05$ compared to the control group. ${ }^{*} \mathrm{P}<0.05$ compared to the cerebral palsy group. 
higher in the cerebral palsy rat pups $(\mathrm{P}<0.05)$, meanwhile, treadmill running lessened $p-G S K-3 \beta / G S K-3 \beta$ ratio by decreasing p-GSK-3 $\beta$ expression of the cerebral palsy rat pups $(\mathrm{P}<0.05)$.

\section{Hippocampal $\beta$-Catenin Expression}

Fig. 8 is Western blot analysis showing hippocampal $\beta$-catenin expression. The $\beta$-catenin expression was higher in the cerebral palsy rat pups $(\mathrm{P}<0.05)$, meanwhile, treadmill running lessened $\beta$-catenin expression of the cerebral palsy rat pups $(\mathrm{P}<0.05)$.
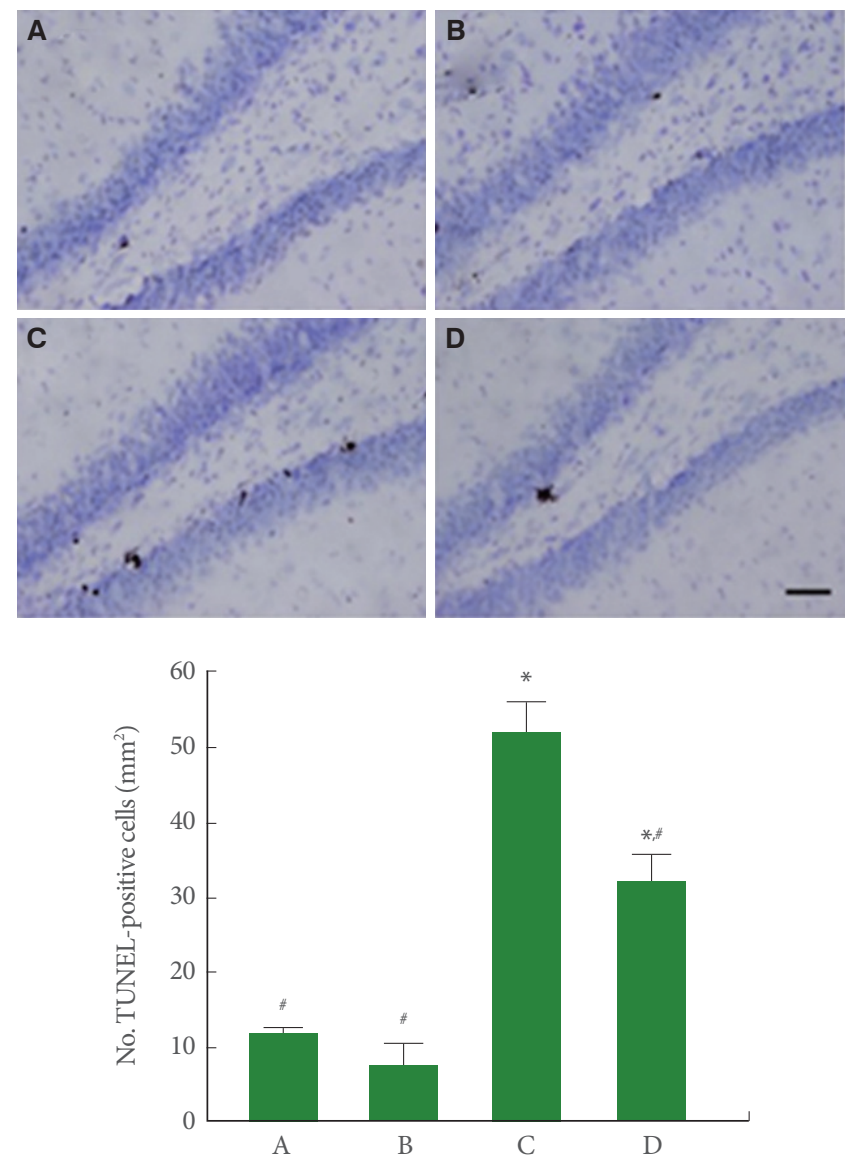

Fig. 3. Effect of treadmill exercise on terminal deoxynucleotidyl transferase-mediated dUTP nick end labeling (TUNEL)-positive cells in the hippocampal dentate gyrus. Upper panel: Photomicrographs of TUNEL-positive cells in the hippocampal dentate gyrus. The scale bar represents $200 \mu \mathrm{m}$. Lower panel: Number of TUNEL-positive cells in each group. A, control group; B, exercise group; $\mathrm{C}$, cerebral palsy group; $\mathrm{D}$, cerebral palsy and exercise group. ${ }^{*} \mathrm{P}<0.05$ compared to the control group. ${ }^{*} \mathrm{P}<0.05$ compared to the cerebral palsy group.

\section{DISCUSSION}

LPS-induced maternal infection is a common cause of preterm birth and neonatal complications [1,2]. Hippocampus-dependent functions, such as learning and memory, was deteriorated following LPS injection [23]. Hao et al. [24] reported that maternal exposure to LPS induced memory impairments in rat pups. The fact that exercise improves learning ability and memory function is well documented in many previous studies $[2,4,6]$. In our study, maternal LPS-injection deteriorated shortterm memory and treadmill running ameliorated this impairments of short-term memory of the cerebral palsy rat pups.

Two important effects of physical exercise are facilitating neurogenesis and suppressing apoptosis $[4,25,26]$. Zhang et al. [9] demonstrated that physical exercise promoted cell proliferation, thereby, improved functional recovery. Cho et al. [27] revealed that treadmill running facilitated cell proliferation, which was assessed by BrdU immunohistochemistry, in the hippocampal dentate gyrus of the depressive rats. In our study, BrdU-positive cell number was decreased in the hippocampal
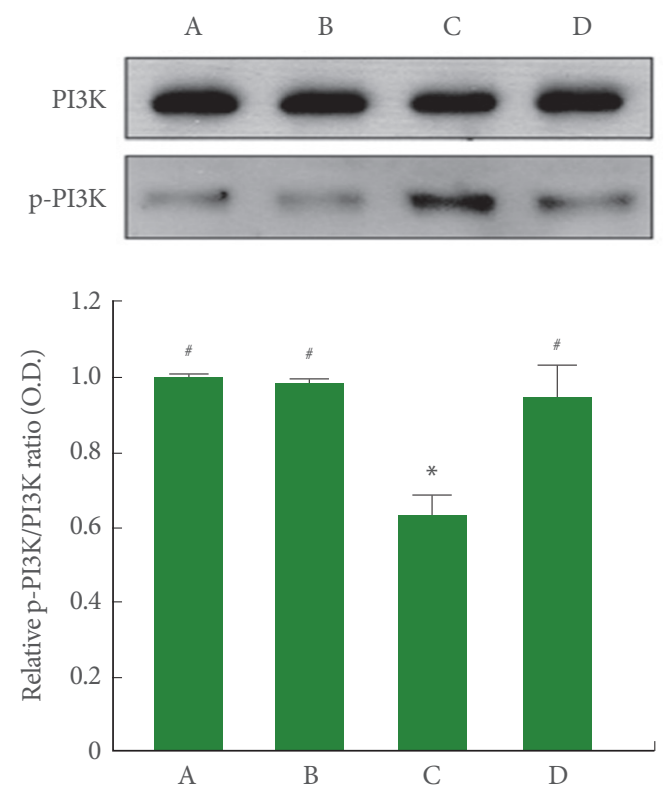

Fig. 4. Effect of treadmill exercise on phosphatidylinositol 3-kinase (PI3K) and phosphorylated PI3K (p-PI3K) expressions in the hippocampus. Upper panel: Representative expressions of $\mathrm{PI} 3 \mathrm{~K}$ and $\mathrm{p}-\mathrm{PI} 3 \mathrm{~K}$ in the hippocampus. Lower panel: Relative $\mathrm{PI} 3 \mathrm{~K}$ and $\mathrm{p}$-PI3K ratio in each group. A, control group; B, exercise group; $\mathrm{C}$, cerebral palsy group; $\mathrm{D}$, cerebral palsy and exercise group. ${ }^{*} \mathrm{P}<0.05$ compared to the control group. ${ }^{*} \mathrm{P}<0.05$ compared to the cerebral palsy group. 

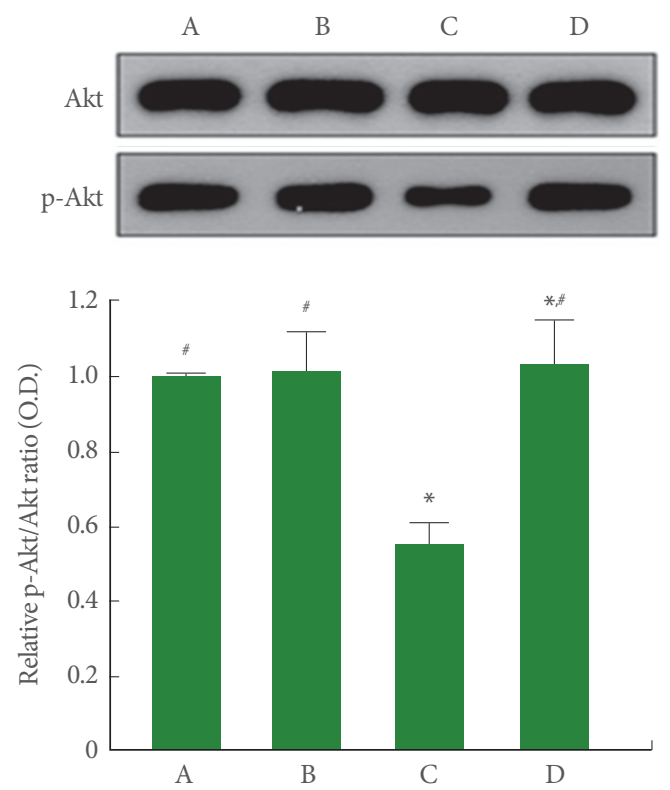

Fig. 5. Effect of treadmill exercise on protein kinase B (Akt) and phosphorylated Akt (p-Akt) expressions in the hippocampus. Upper panel: Representative expressions of Akt and p-Akt in the hippocampus. Lower panel: Relative Akt and p-Akt ratio in each group. A, control group; B, exercise group; C, cerebral palsy group; $\mathrm{D}$, cerebral palsy and exercise group. ${ }^{*} \mathrm{P}<0.05$ compared to the control group. ${ }^{*} \mathrm{P}<0.05$ compared to the cerebral palsy group.

dentate gyrus of the cerebral palsy rat pups, whereas, treadmill running enhanced this BrdU-positive cell number of the cerebral palsy rat pups. DNA fragmentation, one of the characteristics of apoptotic cell death, can be detected by TUNEL staining $[4,6]$. TUNEL-positive cell number in the hippocampal dentate gyrus was enhanced after transient global ischemia, however at their study, treadmill exercise decreased this TUNEL-positive cell number [25]. Treadmill exercise reduced the mRNA expressions of apoptotic factors in cerebral ischemic rats [26]. In our study, hippocampal TUNEL-positive cell number was enhanced in the cerebral palsy rats, whereas, treadmill exercise reduced this TUNEL-positive cell number of the cerebral palsy rat pups.

The PI3K-Akt pathway has a lot involvement in the neuronal proliferation, neuronal survival, and glucose metabolism [28]. PI3K-Akt activation facilitates new cell generation and survival, and then PI3K-Akt signaling exerts a protective role against diverse neuropsychiatric diseases [2,29,30]. Physical exercise is known to activate this pathway and prevent cognitive decline [30]. Fang et al. [31] demonstrated that treadmill exercise activated PI3K-Akt signaling, and then improved hippocampal
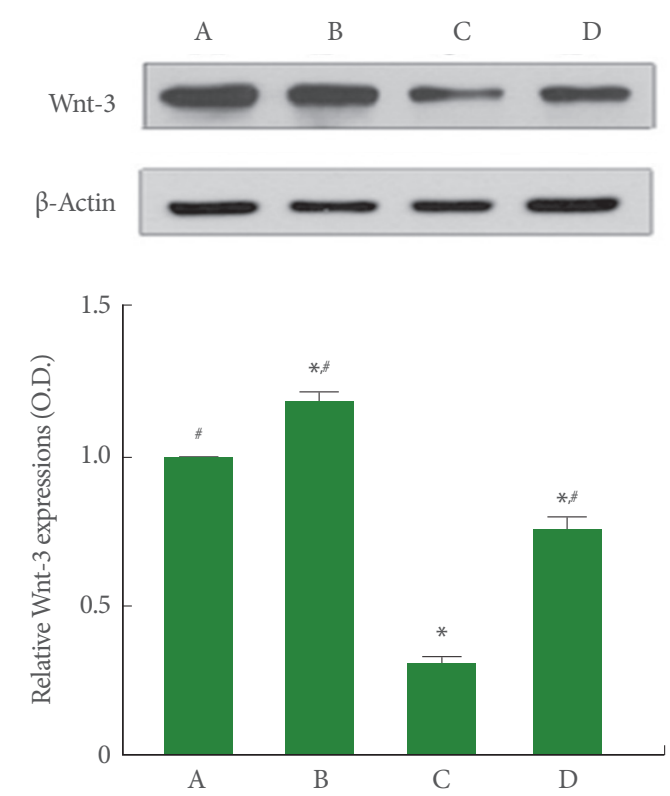

Fig. 6. Effect of treadmill exercise on Wnt-3 expression in the hippocampus. Upper panel: Representative expressions of Wnt3 and $\beta$-actin in the hippocampus. Lower panel: Relative Wnt-3 expressions in each group. A, Control group; B, exercise group; $\mathrm{C}$, cerebral palsy group; D, cerebral palsy and exercise group. ${ }^{*} \mathrm{P}<0.05$ compared to the control group. ${ }^{\#} \mathrm{P}<0.05$ compared to the cerebral palsy group.

function. In our study, hippocampal p-PI3K/PI3K ratio was declined in the cerebral palsy rat pups, however, treadmill exercise restored this $\mathrm{p}-\mathrm{PI} 3 \mathrm{~K} / \mathrm{PI} 3 \mathrm{~K}$ ratio through increasing $\mathrm{PI} 3 \mathrm{~K}$ phosphorylation of the cerebral palsy rat pups. In addition, hippocampal p-Akt/Akt ratio was decreased in the cerebral palsy rat pups, however, treadmill running increased this p-Akt/Akt ratio by increasing Akt phosphorylation of the cerebral palsy rat pups.

PI3K-Akt-Wnt signaling pathway regulates neurogenesis [17]. Hippocampal Wnt expression was increased after voluntary exercise $[12,15]$. In our study, hippocampal Wnt expression was declined in the cerebral palsy rats, however, treadmill running elevated this Wnt expression of the cerebral palsy rat pups.

The effects of GSK-3 $\beta$ on developmental processes are influenced by Wnt signaling. Activation of the Wnt signaling pathway causes inhibition of GSK-3 $\beta$. GSK-3 $\beta$ suppresses neurogenesis by negatively regulating the proliferation of neural precursors. [12]. In our study, p-GSK-3 $\beta /$ GSK-3 $\beta$ ratio was increased in the cerebral palsy rats, however, treadmill exercise decreased this $\mathrm{p}-\mathrm{GSK}-3 \beta / \mathrm{GSK}-3 \beta$ ratio by suppressing GSK-3 $\beta$ phosphorylation of the cerebral palsy rat pups. 

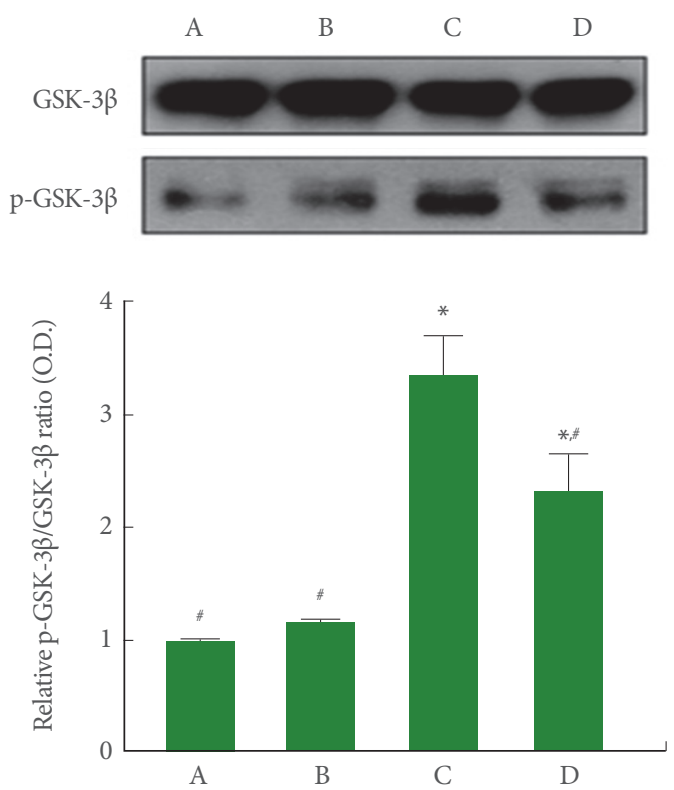

Fig. 7. Effects of treadmill exercise on glycogen synthase kinase$3 \beta$ (GSK- $3 \beta$ ) and phosphorylated GSK-3 $\beta$ (p-GSK-3 $\beta$ ) expressions in the hippocampus. Upper panel: Representative expressions of GSK- $3 \beta$ and p-GSK-3 $\beta$ in the hippocampus. Lower panel: Relative GSK-3 $\beta /$ p-GSK- $3 \beta$ ratio in each group. A, control group; $\mathrm{B}$, exercise group; $\mathrm{C}$, cerebral palsy group; $\mathrm{D}$, cerebral palsy and exercise group. ${ }^{*} \mathrm{P}<0.05$ compared to the control group. ${ }^{*} \mathrm{P}<0.05$ compared to the cerebral palsy group.

Because of $\beta$-catenin is a main ingredient of Wnt signaling, GSK-3 $\beta$ is tightly linked in the Wnt pathway. $\beta$-Catenin is also a well-known substrate of GSK-3 $\beta$. Inhibition of Wnt pathway causes $\beta$-catenin phosphorylation by GSK-3 $\beta$, in contrast, activation of Wnt signaling led to inhibition of GSK- $3 \beta$ and stabilization of cytoplasmic $\beta$-catenin [17]. In our study, hippocampal $\beta$-catenin expression was potentiated in the cerebral palsy rats, however, treadmill running reduced this $\beta$-catenin level of the cerebral palsy rat pups.

Jung and Kim [2] showed that treadmill exercise improved motor ability and memory function of the cerebral palsy rats. This improvement of exercise on symptoms of cerebral palsy occurred through PI3K-Akt pathway activation [2]. As PI3K pathway is associated with urologic disorders including malignancies [32], PI3K signaling appeared as the therapeutic targeting of urologic disorders.

In our study, treadmill exercise ameliorated maternal LPSinduced impairments of short-term memory by enhancing neuronal generation and decreasing apoptotic cell death. Neuronal generation was facilitated via activating PI3K-Akt-Wnt
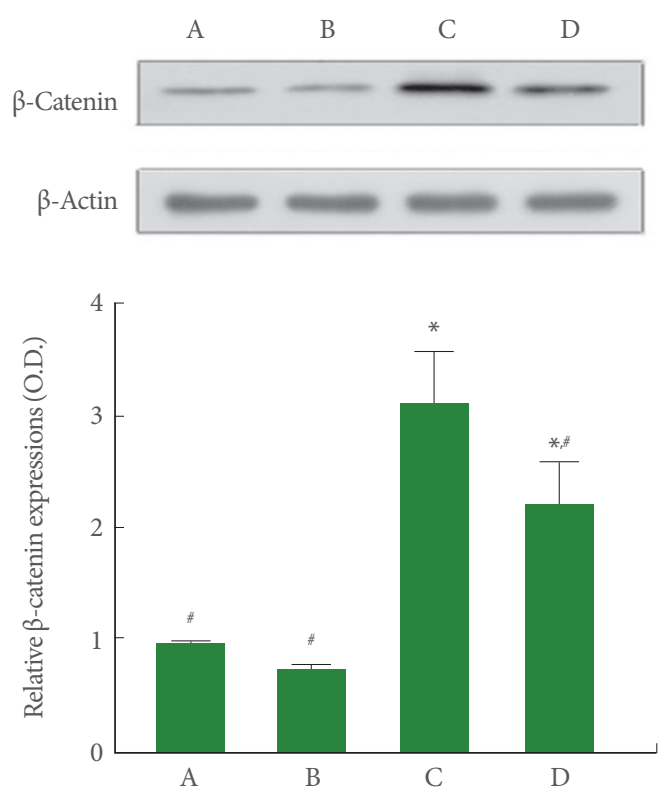

Fig. 8. Effects of treadmill exercise on $\beta$-catenin expression in the hippocampus. Upper panel: Representative expression of $\beta$-catenin and $\beta$-actin in the hippocampus. Lower panel: Relative $\beta$-catenin expressions in each group. A, control group; $\mathrm{B}$, exercise group; $\mathrm{C}$, cerebral palsy group; $\mathrm{D}$, cerebral palsy and exercise group. ${ }^{*} \mathrm{P}<0.05$ compared to the control group. ${ }^{~} \mathrm{P}<0.05$ compared to the cerebral palsy group.

pathway, and then led to GSK-3 $\beta$ inhibition and $\beta$-catenin stabilization. The results of this study showed that short-term memory improvement due to treadmill running in cerebral palsy occurs via activation of the PI3K-Akt-Wnt pathway.

\section{AUTHOR CONTRIBUTION STATEMENT}

- Full access to all the data in the study and takes responsibility for the integrity of the data and the accuracy of the data analysis: JWC

- Study concept and design: JWJ, JHH

- Acquisition of data: SYJ, DYK

- Analysis and interpretation of data: SYJ, DYK

- Drafting of the manuscript: JWC

- Critical revision of the manuscript for important intellectual content: JWJ, JHH

- Statistical analysis: SYJ, DYK

- Administrative, technical, or material support: YRC, HHC

- Study supervision: JWJ, JHH 


\section{REFERENCES}

1. Hermansen MC, Hermansen MG. Perinatal infections and cerebral palsy. Clin Perinatol 2006;33:315-33.

2. Jung SY, Kim DY. Treadmill exercise improves motor and memory functions in cerebral palsy rats through activation of PI3K-Akt pathway. J Exerc Rehabil 2017;13:136-42.

3. Keogh JM, Badawi N. The origins of cerebral palsy. Curr Opin Neurol 2006;19:129-34.

4. Baek SS, Kim SH. Treadmill exercise ameliorates symptoms of Alzheimer disease through suppressing microglial activation-induced apoptosis in rats. J Exerc Rehabil 2016;12:526-34.

5. Chaudhry K, Rogers R, Guo M, Lai Q, Goel G, Liebelt B, et al. Matrix metalloproteinase-9 (MMP-9) expression and extracellular signal-regulated kinase 1 and 2 (ERK1/2) activation in exercise-reduced neuronal apoptosis after stroke. Neurosci Lett 2010;474:10914.

6. Kim SE, Ko IG, Kim BK, Shin MS, Cho S, Kim CJ, et al. Treadmill exercise prevents aging-induced failure of memory through an increase in neurogenesis and suppression of apoptosis in rat hippocampus. Exp Gerontol 2010;45:357-65.

7. Shin MS, Ko IG, Kim SE, Kim BK, Kim TS, Lee SH, et al. Treadmill exercise ameliorates symptoms of methimazole-induced hypothyroidism through enhancing neurogenesis and suppressing apoptosis in the hippocampus of rat pups. Int J Dev Neurosci 2013;31:21423.

8. Pereira AC, Huddleston DE, Brickman AM, Sosunov AA, Hen R, McKhann GM, et al. An in vivo correlate of exercise-induced neurogenesis in the adult dentate gyrus. Proc Natl Acad Sci U S A 2007;104:5638-43.

9. Zhang L, Hu X, Luo J, Li L, Chen X, Huang R, et al. Physical exercise improves functional recovery through mitigation of autophagy, attenuation of apoptosis and enhancement of neurogenesis after MCAO in rats. BMC Neurosci 2013;14:46.

10. Wu Y, Peng H, Cui M, Whitney NP, Huang Y, Zheng JC. CXCL12 increases human neural progenitor cell proliferation through Akt1/FOXO3a signaling pathway. J Neurochem 2009;109:1157-67.

11. Clevers $H$, Nusse R. Wnt/ $\beta$-catenin signaling and disease. Cell 2012;49:1192-205.

12. Lee HJ, Baek SS. Role of exercise on molecular mechanisms in the regulation of antidepressant effects. J Exerc Rehabil 2017;13:617-20

13. Gogolla N, Galimberti I, Deguchi Y, Caroni P. Wnt signaling mediates experience-related regulation of synapse numbers and mossy fiber connectivities in the adult hippocampus. Neuron 2009;62:51025.
14. Bayod S, Mennella I, Sanchez-Roige S, Lalanza JF, Escorihuela RM, Camins A, et al. Wnt pathway regulation by long-term moderate exercise in rat hippocampus. Brain Res 2014;1543:38-48.

15. Stranahan AM, Lee K, Becker KG, Zhang Y, Maudsley S, Martin B, et al. Hippocampalgene expression patterns underlying the enhancement of memory by running in aged mice. Neurobiol Aging 2010;31:1937-49.

16. Liu C, Li Y, Semenov M, Han C, Baeg GH, Tan Y, et al. Control of beta-catenin phosphorylation/degradation by a dual-kinase mechanism. Cell 2002;108:837-47.

17. Tiwari SK, Seth B, Agarwal S, Yadav A, Karmakar M, Gupta SK, et al. Ethosuximide induces hippocampal neurogenesis and reverses cognitive deficits in an amyloid- $\beta$ toxin-induced Alzheimer rat model via the phosphatidylinositol 3-kinase (PI3K)/Akt/Wnt/ $\beta$-catenin pathway. J Biol Chem 2015;290:28540-58.

18. Valvezan AJ, Klein PS. GSK-3 and Wnt signaling in neurogenesis and bipolar disorder. Front Mol Neurosci 2012;5:1.

19. Sakamoto K, Aschenbach WG, Hirshman MF, Goodyear LJ. Akt signaling in skeletal muscle: regulation by exercise and passive stretch. Am J Physiol Endocrinol Metab 2003;285: E1081-8.

20. Luo J. The role of GSK3beta in the development of the central nervous system. Front Biol (Beijing) 2012;7:212-20.

21. Lee E, Salic A, Kruger R, Heinrich R, Kirschner MW. The roles of APC and axin derived from experimental and theoretical analysis of the Wnt pathway. PLoS Biol 2003;1:116-32.

22. Kim SE, Han JH, Ko IG, Kim CJ, Kim KH. Alpha1-adrenergic receptor antagonist tamsulosin ameliorates aging-induced memory impairment by enhancing neurogenesis and suppressing apoptosis in the hippocampus of old-aged rats. Anim Cells Syst 2017;21:40411.

23. Sparkman NL, Kohman RA, Garcia AK, Boehm GW. Peripheral lipopolysaccharide administration impairs two-way active avoidance conditioning in C57BL/6J mice. Physiol Behav 2005;85:27888.

24. Hao LY, Hao XQ, Li SH, Li XH. Prenatal exposure to lipopolysaccharide results in cognitive deficits in age-increasing offspring rats. Neuroscience 2010;166:763-70.

25. Shim YJ, Kim SS, Kim JY, Shin MS, Kim CJ. Treadmill exercise improves short-term memory by suppressing ischemia-induced apoptosis of neuronal cells in gerbils. Neurosci Lett 2004;372:25661.

26. Tong L, Shen H, Perreau VM, Balazs R, Cotman CW. Effects of exercise on gene-expression profile in the rat hippocampus. Neurobiol Dis 2001;8:1046-56.

27. Cho JW, Jung SY, Lee SW, Lee SJ, Seo TB, Kim YP, et al. Treadmill 
exercise ameliorates social isolation-induced depression through neuronal generation in rat pups. J Exerc Rehabil 2017;13:627-33.

28. Brazil DP, Yang ZZ, Hemmings BA. Advances in protein kinase B signalling: AKTion on multiple fronts. Trends Biochem Sci 2004; 29:233-42.

29. Chavali PL, Saini RK, Matsumoto Y, Ågren H, Funa K. Nuclear orphan receptor TLX induces Oct- $3 / 4$ for the survival and maintenance of adult hippocampal progenitors upon hypoxia. J Biol Chem 2011;286:9393-404.
30. Lista I, Sorrentino G. Biological mechanisms of physical activity in preventing cognitive decline. Cell Mol Neurobiol 2010;30:493-503.

31. Fang ZH, Lee CH, Seo MK, Cho H, Lee JG, Lee BJ, et al. Effect of treadmill exercise on the BDNF-mediated pathway in the hippocampus of stressed rats. Neurosci Res 2013;76:187-94.

32. Tran P, Nguyen C, Klempner SJ. Targeting the phosphatidylinositol-3-kinase pathway in gastric cancer: Can omics improve outcomes? Int Neurourol J 2016;20(Suppl 2):S131-40. 